\title{
A clinical study on the effect of shatavari churna and shatavari taila uttarbasti in atyartava
}

\author{
Pratibha Ramchandani, Sunita Suman \\ Department of Prasuti Tantra, Institute of Medical Sciences, Banaras Hindu University, Varanasi, India
}

\begin{abstract}
Introduction: Heavy and prolonged bleeding during menses is one of the most common complaints encountered by gynecologists across the globe. The word "Atyartava" literally means excessive bleeding during menstruation which is a cardinal feature in a number of menstrual disorders described in the Ayurvedic classics. Atyartava can be correlated to "Menorrhagia" in modern literature. The aim of the present study was to evaluate "the effect of Shatavari Churna and Shatavari Taila Uttarbasti in Atyartava." Materials and Methods: A total of 40 patients were selected for the present research work and randomly divided into two groups of 20 patients each. In Group A, patients were treated with $3 \mathrm{~g}$ of Shatavari (Asparagus racemosus) Churna orally twice daily for 3 months, while in Group B, patients were given $3 \mathrm{~g}$ of Shatavari Churna orally twice daily for 3 months along with Shatavari Taila Uttarbasti on $9^{\text {th }}, 10^{\text {th }}$, and $11^{\text {th }}$ days of menses for 3 consecutive months. After conducting the clinical trial on 40 patients, the data were obtained and analyzed statistically. Results: It was observed that both the groups were significantly effective in ameliorating the symptoms of Atyartava. However, on comparison of both Groups A and B, Group B showed better results. Conclusion: It showed that the specific therapy (Uttarbasti Chikitsa with shatavari oil) along with oral administration of Shatavari Churna was more effective in the treatment of Atyartava, in comparison to Shatavari Churna alone. The effects of Shatavari on menorrhagia were attributed mainly to its phytoestrogenic action.
\end{abstract}

Key words: Asparagus racemosus, atyartava, ayurveda, menorrhagia, shatavari, uttarbasti

\section{INTRODUCTION}

A yurveda is an ancient science of healing that enhances longevity. In Charak Samhita, Acharya Agnivesh has dedicated an entire chapter on gynecological disorders. The chapter begins with a grand compliment to the women, by referring them as "excellent root for progeny." Acharya had a deep concern for the diseases of female genital organs as he believed that they had the potential of adversely affecting our coming generations.

"Atyartava" is a cardinal feature in a number of menstrual disorders described in Ayurvedic texts such as Pittaj, Ratkayoni and Lohitkshara Yonivyapada, Kunapgandhi Artavadusti, Vikuta Jataharini, and Asrigdara.

Atyartava has been correlated to "menorrhagia" in modern literature. The term "menorrhagia" is from the Greek word, men meaning "menses" and rrhagia meaning "burst forth." It denotes cyclic bleeding at a regular interval, which is either excessive in amount or duration. Excessive bleeding can lead to anemia which presents as fatigue, shortness of breath, weakness, giddiness, tingling sensation and numbness in the body, and several other troublesome ailments. The purpose of the present study was to control the excessive bleeding, restoring the health status of the woman, and prevention of other gynecological and systemic complications.

\section{MATERIALS AND METHODS}

Materials and Methods were discussed under following headings-Selection of drugs and the criteria for their selection,

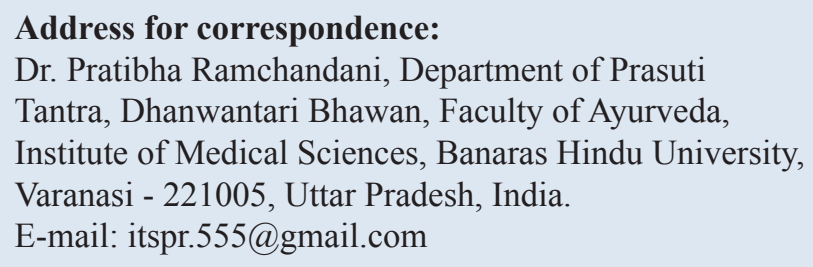

Received: 01-09-2018

Revised: 13-11-2018

Accepted: 21-11-2018 
Selection of patients, Inclusion criteria and Exclusion criteria, Demographic profile, History taking, Examinations conducted, Investigations performed, Grouping of patients on the basis of route of drug administration, Scoring of complaints, Follow-ups, Statistical analysis and Assessment of results.

\section{Criteria for the Selection of Drugs}

Shatavari (Asparagus racemosus) has authentic references, ${ }^{[1]}$ easily available, economical, and safe drug. Shatavari has madhura-tikta rasa, guru snigdha guna, madhur vipaka, and sheet virya ${ }^{[2]}$ Due to these properties, it is able to pacify vata and pitta. It has raktapittashamak and astringent (samgrahi) properties. Modern researches have shown that it has estrogenic ${ }^{[3]}$ and astringent ${ }^{[4]}$ action. It also has anti-ulcergenic and antisecretory activity. ${ }^{[5]}$ It is also proven to be an adaptogen ${ }^{[3]}$ and antidepressant. ${ }^{[6]}$ Tila taila is used as a media in the preparation of shatavari taila which has yogvahi and tridosha-shamaka properties. ${ }^{[7]}$

\section{Physical and Chemical Analysis of Trial Drug}

Identification of drug was done by the Department of Dravyaguna and preparation of drug was done in the Department of Rasa-Shastra and Bhaishajya Kalpana with standard methods. (Ref. No.PT/AY/IMS/2016-2017/947).

Again drug identification and analysis were done in the Department of Botany, Faculty of Science and Department of Chemical Engineering and Technology, Banaras Hindu University, Varanasi (Ref. No. ChE/2018-19/440).

\section{Selection of Cases}

Patients coming to the outpatient department of Prasuti Tantra, S.S. Hospital, Banaras Hindu University, Varanasi, with the complaints of excessive bleeding either in amount or duration or both during menstruation for at least three consecutive cycles were randomly selected for the present study.

\section{Inclusion Criteria}

Married women of the age group of 18-45 years having a complaint of excessive menstrual bleeding from three cycles or more than three cycles were included in the study.

\section{Exclusion Criteria}

Unmarried patients; women $<18$ years or $>45$ years of age; patients associated with any currently ongoing research study or using any contraceptive method; patients having history of recent delivery or abortion, with any specific disease, especially of chronic nature such as marked anemia,
T.B., hypertension, diabetes, hypo-/hyper-thyroidism, cardiac disease, renal disease, jaundice, or any other disorders influencing general physical health and ultimately influencing menses; patients having organic lesion of reproductive system such as benign or malignant growth, extensive cervical erosion, unhealthy cervix, cervical polyp, pelvic inflammatory disease, uterovaginal prolapse, endometriosis, and tubercular endometritis; psychiatric patients, patients having any allergy to the drugs; and patients not fulfilling the criteria of pro forma were excluded from the present study.

\section{Study Design}

A complete history of the patient was noted on the pre-designed specific pro forma. Detailed interrogation was made regarding the chief complaints, history of present illness, surgical history, and history of any gynecological treatment. History of blood transfusion, family history, marital status, status of personal hygiene, personal history, and socioeconomic status were also noted. Initially, 62 patients were registered, in which 8 cases were excluded from the study on the basis of history.

In remaining 54 cases, Dashvidha Pareeksha, General, Systemic, and Local examination including per speculum and per vaginum examinations were performed, and the findings were noted. After complete examination, six cases were excluded from the study.

\section{Investigations}

In remaining 48 cases, the following investigations were done. $\mathrm{Hb} \%$, total leukocyte count, differential leukocyte count, erythrocyte sedimentation rate, bleeding time, clotting time, platelet count, fasting blood sugar, and blood urea were obtained. Urine was analyzed for routine and microscopic examination. Ultrasonography was done to note the condition of the uterus and adnexa or for any other pelvic pathology and thickness of endometrium. Thyroid profile - T3 and T4, thyroid-stimulating hormone, and serum estradiol levels were obtained. After investigations, six cases were excluded. Finally, 42 patients were taken for the study, of which two patients did not come for regular follow-up. A total of 40 patients were selected for the present study and scoring was done.

\section{Scoring}

Scoring was done entirely on the basis of patients' statement. For assessment of the amount of blood loss, the cases were advised to use standard size diapers or sanitary pads, i.e., 6" $\times 3$ " $\times 1.5$ " of average weight made of cotton and asked to remove diaper only when it was properly soaked and count the diapers used per day during menstruation. Scoring was done after analyzing the parameters [Tables 1 and 2]. 


\begin{tabular}{|c|c|c|c|}
\hline Parameter & Criteria & & Score \\
\hline \multirow[t]{4}{*}{ Amount of menstrual bleeding } & Complete soakage of $1-2$ pads in $24 \mathrm{~h}$ & Average & 0 \\
\hline & Complete soakage of $3-4$ pads in $24 \mathrm{~h}$ & Moderately excessive & 1 \\
\hline & Complete soakage of $5-6$ pads in $24 \mathrm{~h}$ & Excessive & 2 \\
\hline & Complete soakage of 7 or more pads in $24 \mathrm{~h}$ & Very excessive & 3 \\
\hline \multirow[t]{4}{*}{ Duration of menstrual bleeding } & $2-4$ days & Normal & 0 \\
\hline & $4-6$ days & Moderately prolonged & 1 \\
\hline & $6-8$ days & Prolonged & 2 \\
\hline & $>8$ days & Very prolonged & 3 \\
\hline \multirow[t]{4}{*}{ Pain in the abdomen during menstruation } & No pain & Absent & 0 \\
\hline & $\begin{array}{l}\text { Woman complains of pain but does not } \\
\text { require any drug for relief }\end{array}$ & Mild & 1 \\
\hline & $\begin{array}{l}\text { Woman complains of pain and takes one } \\
\text { or two doses of the drug for relief. The pain } \\
\text { does not affect her routine work }\end{array}$ & Moderate & 2 \\
\hline & $\begin{array}{l}\text { Woman complains of pain and takes } 3-4 \\
\text { doses of the drug for relief. The pain affects } \\
\text { her routine work and may even prevent } \\
\text { verbal communication }\end{array}$ & Severe & 3 \\
\hline
\end{tabular}

Table 2: Scoring of associated signs and symptoms

\begin{tabular}{llc} 
Symptom & Criteria & Scoring \\
\hline Backache & Absent & 0 \\
Nausea & Present & 1 \\
& Absent & 0 \\
Giddiness & Present & 1 \\
& Absent & 0 \\
Tingling sensation and numbness & Present & 1 \\
& Absent & 0 \\
& Present & 1 \\
\hline
\end{tabular}

\section{Grouping of Cases}

After a detailed history, complete examination, and investigations, 40 cases were selected and divided into two groups according to the different treatment schedules. In Group A, patients were treated with $3 \mathrm{~g}$ of Shatavari Churna orally twice daily for 3 consecutive months, while in Group B, patients were given $3 \mathrm{~g}$ of Shatavari Churna orally twice daily for 3 months along with Shatavari Taila Uttarbasti on $9^{\text {th }}, 10^{\text {th }}$, and $11^{\text {th }}$ days of menses for 3 consecutive months.

\section{Follow-Up}

Total four follow-ups were done at a regular interval of 1 month. Three follow-ups were treated with medicine and last IV fluorouracil was recorded after the withdrawal of drug to see the improvement in sign, symptoms, and change in specific investigations. During each follow-up change in amount, duration, color, and consistency of menstrual blood and relief in pain in the abdomen during menses were noted. Endometrial thickness and serum estradiol level were also noted in I and IV follow-ups.

\section{ASSESSMENT OF RESULT}

Results were assessed on the basis of following parameters:

i. Average amount of menstrual blood loss.

ii. Normal duration of menstrual blood loss.

iii. Normal color of menstrual blood loss.

iv. Normal consistency of menstrual blood loss.

v. Relief in pain in abdomen during menses.

vi. Relief in associated symptoms.

vii. Normal endometrial thickness.

viii. Normal serum estradiol.

1. Cured: All the above parameters were fulfilled.

2. Markedly improved: 6-7 of the above eight parameters were fulfilled.

3. Improved: 4-5 of the above eight parameters were fulfilled.

4. Low improved: $2-3$ of the above eight parameters were fulfilled.

5. Unchanged: None of the eight parameters were fulfilled.

\section{Statistical Analysis}

The data collected were transferred to the master chart showing various items/variables in columns and subjects in rows. The analysis of data was done using statistical software SPSS version 16.0. The items on demographic profile and 
personal characteristics were summarized using univariate and bivariate frequency tables, percentage, and graphs, and for continuous variables, mean and standard deviation were determined.

\section{Intragroup (Within the Group) Comparison}

To test the significance of mean of the difference of paired observations (BT versus AT), paired $t$-test was applied. Wherever the data did not satisfy the assumptions of parametric test, non-parametric test, namely Wilcoxon signed-rank test, was applied. In case of repeated measurements of the same subject for various follow-ups, repeated measure analysis of variance will be applicable, whereas a corresponding non-parametric test applicable here will be Friedman Chi-square test.

\section{Intergroup Comparison (Between the Groups)}

To test the significance of difference of means of two independent groups, unpaired $t$-test (independent sample $t$-test) was applied. Wherever the data did not satisfy the assumptions of parametric test, non-parametric test, namely Wilcoxon-Mann-Whitney $U$-test, was applied. $P<0.05$ was considered as statistically significant.

\section{OBSERVATIONS AND RESULTS}

The results are shown in Tables 3-5 and Graphs 1-11.

Initially, an excessive amount of bleeding was seen in $12(60 \%)$ women in each of Group A and Group B, respectively. In Group A, it was gradually relieved up to III follow-up and no change was seen in $2(10 \%)$ women during IV follow-up. In Group B, change in the amount of blood loss was seen during II follow-up and it was totally relieved in all the patients by IV follow-up.

Initially, moderately excessive amount of bleeding was seen in 1 (5\%) woman in Group A and no woman in Group B. Change in amount of bleeding was noticed from the I follow-up, and it was seen in $7(35 \%)$ women, while during II and III follow-ups, it was seen in $12(60 \%)$ and $14(70 \%)$ women, respectively, and during IVfollow-up, it was present in 15 (75\%) women of Group A. In Group B, the amount of bleeding was changed from the I follow-up and noticed in $11(55 \%)$ women during I follow-up and $13(65 \%)$ and $6(30 \%)$ women, respectively, during IIand III follow-ups. In IVfollow-up, it was present in $4(20 \%)$ women of Group B.

Initially, normal duration of bleeding was not found in any women in Group A, while only $1(5 \%)$ woman had normal duration of bleeding in Group B. During III and IV follow-up, it was seen in $4(20 \%)$ women in Group A and $13(65 \%)$ women in Group B. On comparison between initial and different follow-ups in both the groups, the results were highly significant during I, II, III, and IV follow-ups in both the groups. On comparison between Groups A and B, the results were found non-significant during I follow-up, but highly significant results were seen during II, III, and IV follow-ups in Group B in comparison to Group A.

Initially, the absence of pain in the abdomen during menses was seen in $2(10 \%)$ women in Group A, and only $1(5 \%)$ woman had no pain in Group B. During III follow-up, it was seen in $3(15 \%)$ women in Group A and $7(35 \%)$

\begin{tabular}{|c|c|c|c|c|c|}
\hline \multirow[t]{2}{*}{ Chief complaints } & Total cases $n=40$ & Group A n=20 & Group B $n=20$ & $\chi^{2}$ test & $P$ value \\
\hline & $n(\%)$ & $n(\%)$ & $n(\%)$ & & \\
\hline Heavy bleeding during menses & $40(100)$ & $20(100)$ & $20(100)$ & 0.00 & $P>0.05$ N.S. \\
\hline Clots during menses & $38(95)$ & $19(95)$ & $19(95)$ & 0.00 & $P>0.05$ N.S. \\
\hline Foul smell of menstrual blood & $4(10)$ & $1(5)$ & $3(15)$ & 1.05 & P>0.05 N.S. \\
\hline Pain in abdomen during menses & $37(92.5)$ & $18(90)$ & 19 (95) & 0.360 & $P>0.05$ N.S. \\
\hline
\end{tabular}

Table 4: Incidence of associated symptoms in total cases and both the groups

\begin{tabular}{|c|c|c|c|c|c|}
\hline \multirow[t]{2}{*}{ Associated symptoms } & Total cases $n=40$ & Group A $n=20$ & Group B $n=20$ & \multirow[t]{2}{*}{$\chi^{2}$ test } & \multirow[t]{2}{*}{$P$ value } \\
\hline & $n(\%)$ & $n(\%)$ & $n(\%)$ & & \\
\hline Back ache & $40(100)$ & $20(100)$ & $20(100)$ & 0.00 & $P>0.05$ N.S. \\
\hline Nausea & $36(90)$ & $18(90)$ & $18(90)$ & 0.00 & $P>0.05$ N.S. \\
\hline Giddiness & $33(82.5)$ & $17(85)$ & $16(80)$ & 0.173 & $P>0.05$ N.S. \\
\hline Tingling sensation and numbness & $33(82.5)$ & $17(85)$ & $16(80)$ & 0.173 & $P>0.05$ N.S. \\
\hline
\end{tabular}


women in Group B. Further, it was seen in $3(15 \%)$ women in Group A and $12(60 \%)$ in Group B during IV follow-up. On comparison between initial and different follow-ups

\begin{tabular}{|c|c|}
\hline Parts & $\begin{array}{l}\text { Phytoconstituents of Shatavari (Asparagus } \\
\text { racemosus) }{ }^{[8]}\end{array}$ \\
\hline Flowers & Quercetin, hyperoside, and rutin \\
\hline Fruits & $\begin{array}{l}\text { Quercetin, rutin hyperoside. Anthocyanins, } \\
\text { sitosterol, stigmasterol, and sarsasapogenin }\end{array}$ \\
\hline Leaves & Rutin, diosgenin \\
\hline Root & $\begin{array}{l}\text { Saponins, sapogenin, shatavarins, } \\
\text { sarsapogenin, and kaempferol }\end{array}$ \\
\hline
\end{tabular}

in both the groups, the results were highly significant during I, II, III, and IV follow-ups in both the groups. On comparison between Groups A and B, the results were found non-significant during I follow-up, but significant results were seen during II and III follow-ups and highly significant results were seen in IV follow-up in Group B in comparison to Group A.

Initially, dark red color of menstrual blood was found in $14(70 \%)$ and $15(75 \%)$ women in Groups A and B, respectively. Brown color of menstrual blood was found in $6(30 \%)$ and $5(25 \%)$ women of Groups A and B, respectively. Change in color of menstrual blood was seen from the II follow-up in both the groups. During III follow-up, bright red color of menstrual blood was present in $7(35 \%)$ and

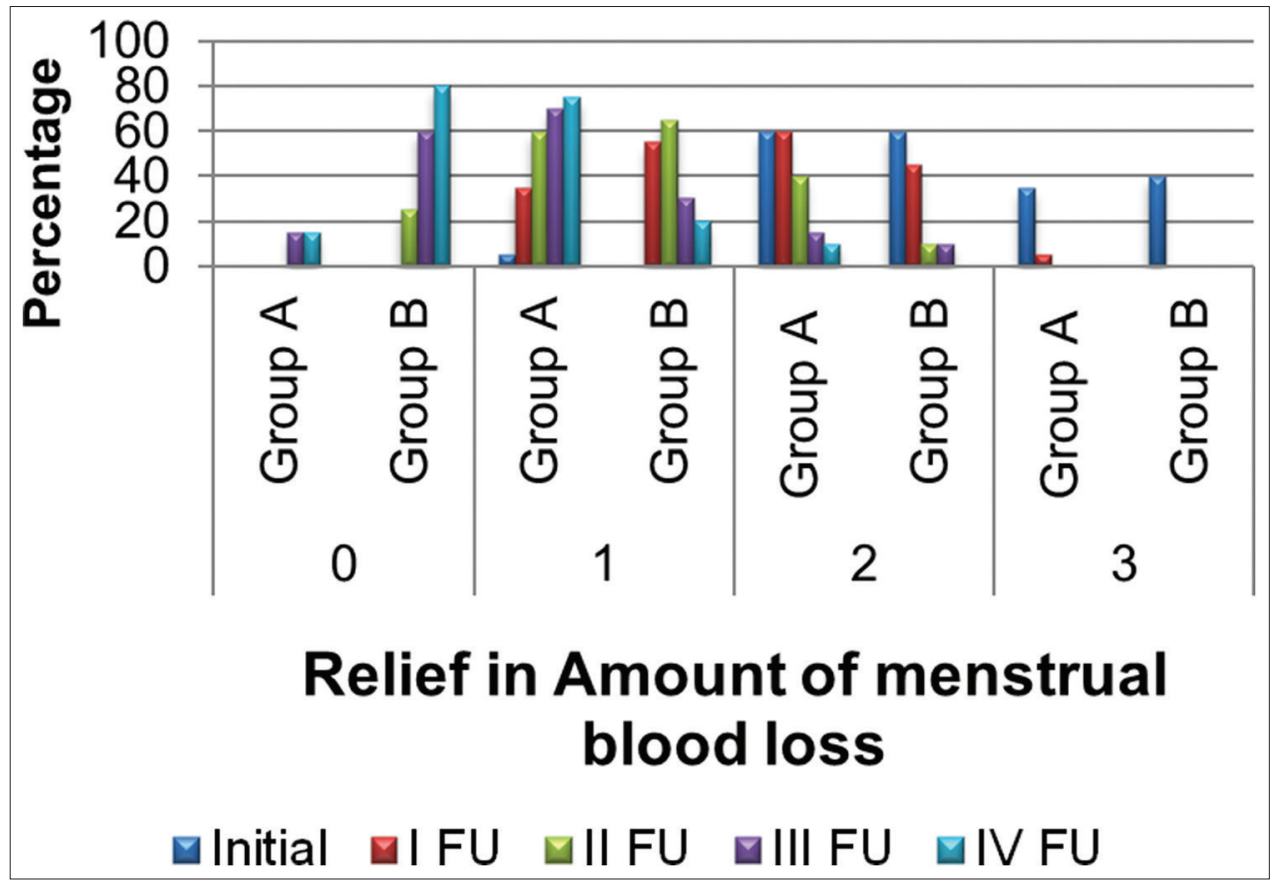

Graph 1: Changes in the amount of blood loss in different follow-ups in both the groups

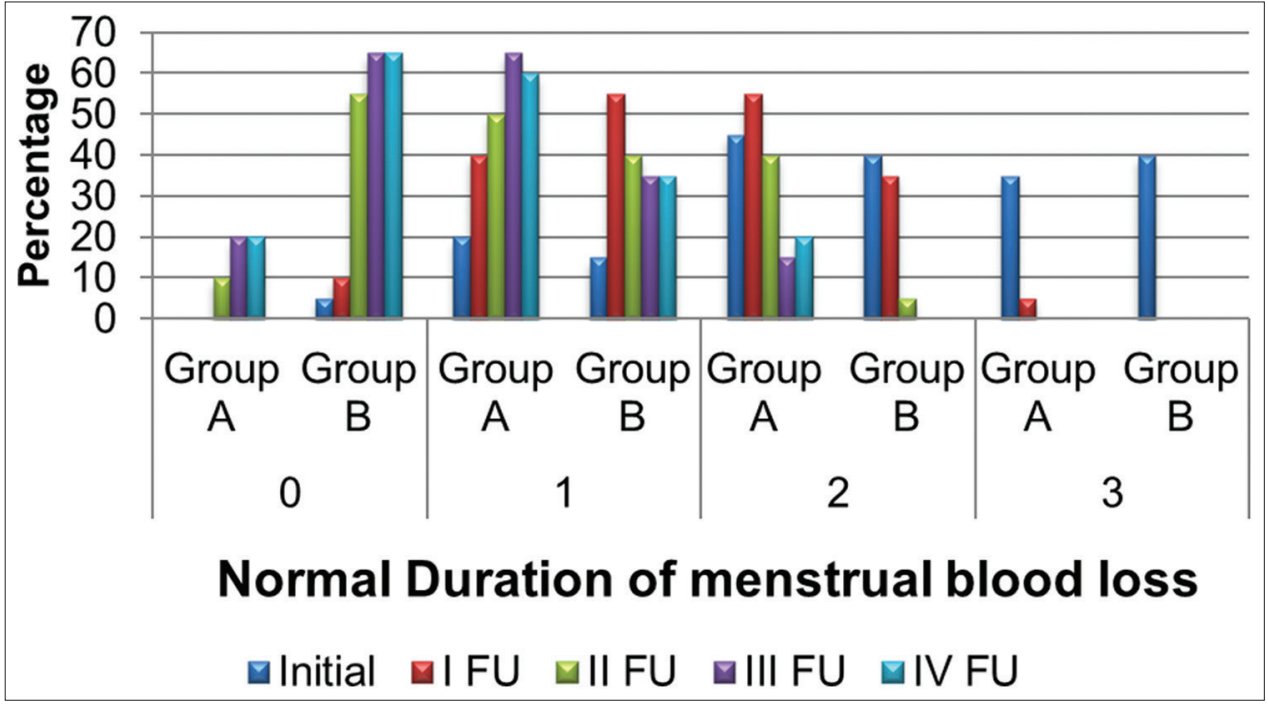

Graph 2: Changes in the duration of blood loss in different follow-ups in both the groups 


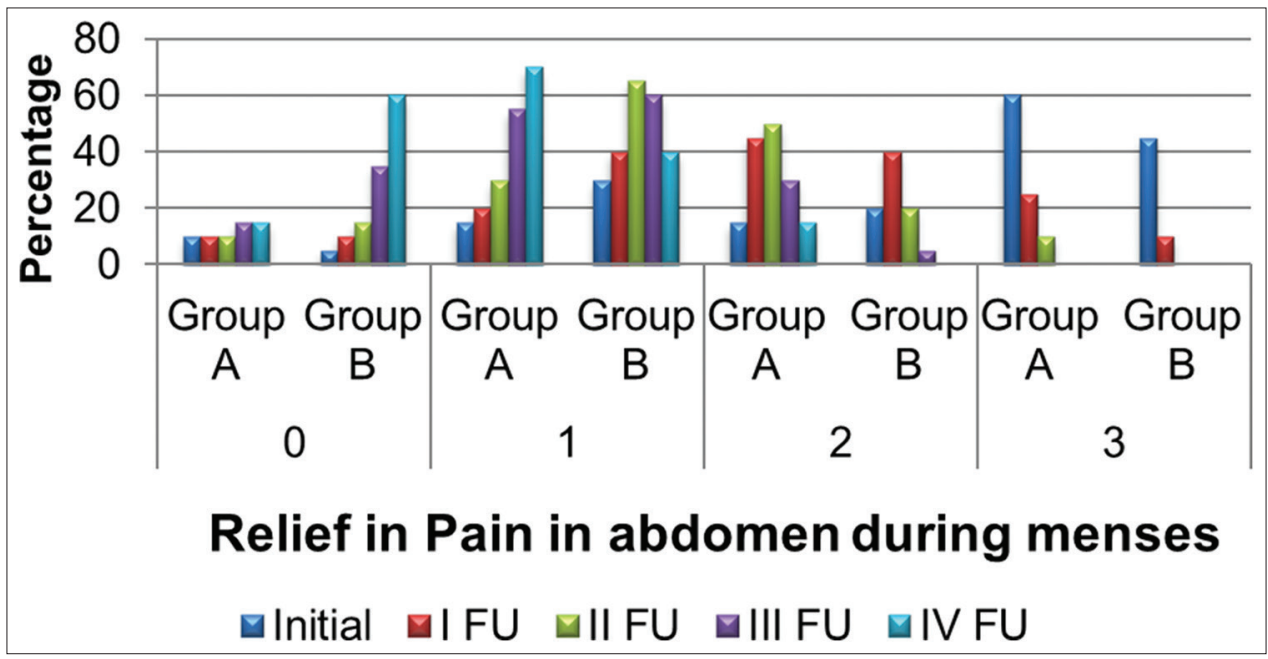

Graph 3: Changes in the pain in abdomen during menses in different follow-ups in both the groups

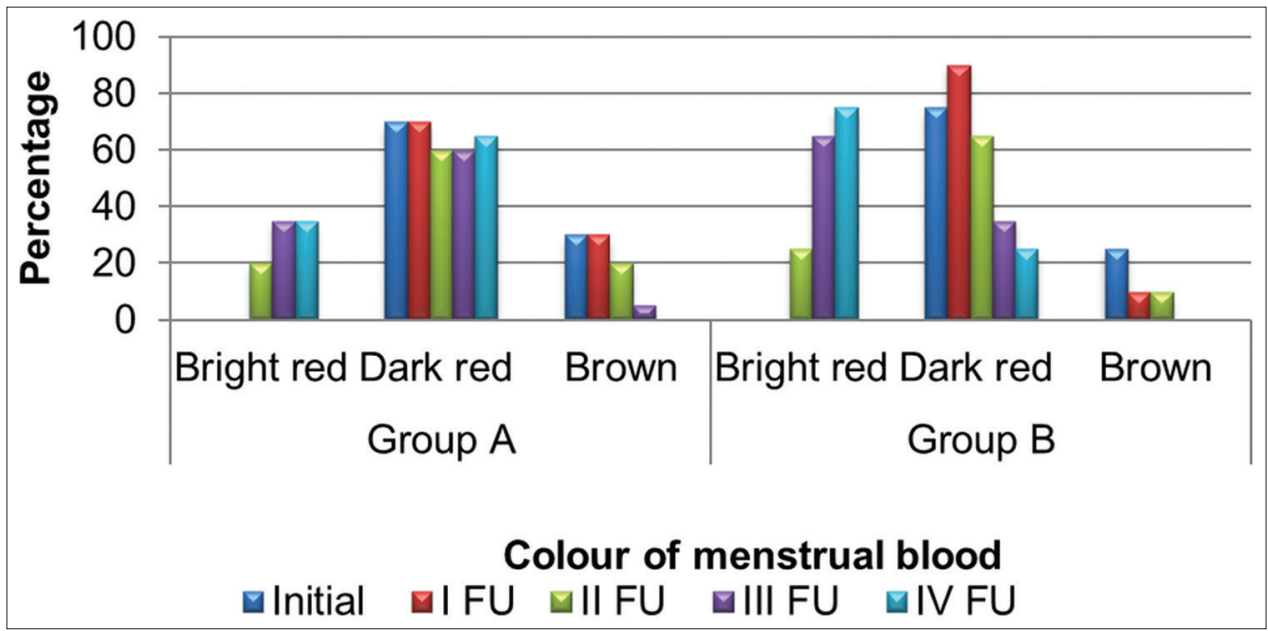

Graph 4: Changes in the colour of menstrual blood in different follow-ups in both the groups

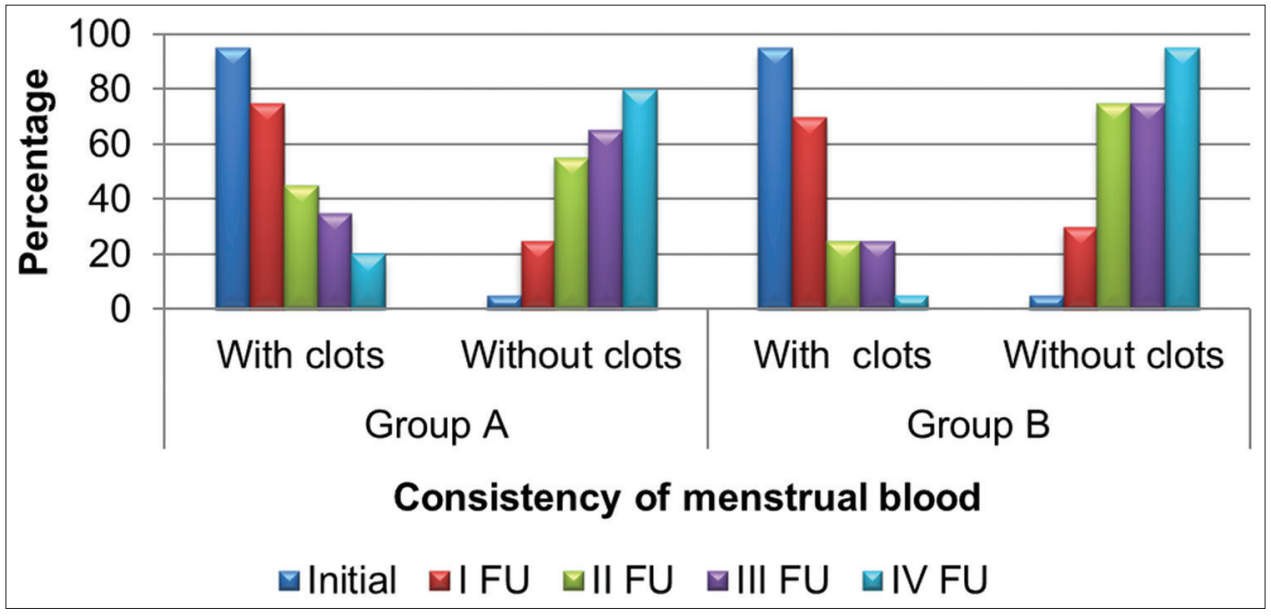

Graph 5: Changes in the consistency of menstrual blood in different follow-ups in both the groups

$13(65 \%)$ women in Groups A and B, respectively, while during IV follow-up, it was present in 7 (35\%) and $15(75 \%)$ women in Groups A and B, respectively. On comparison between initial and different follow-ups, the results were found highly significant in both Groups A and B. On comparison between Groups A and B, the results were found non-significant during I, II, and III follow-ups but significant during IV follow-up. 


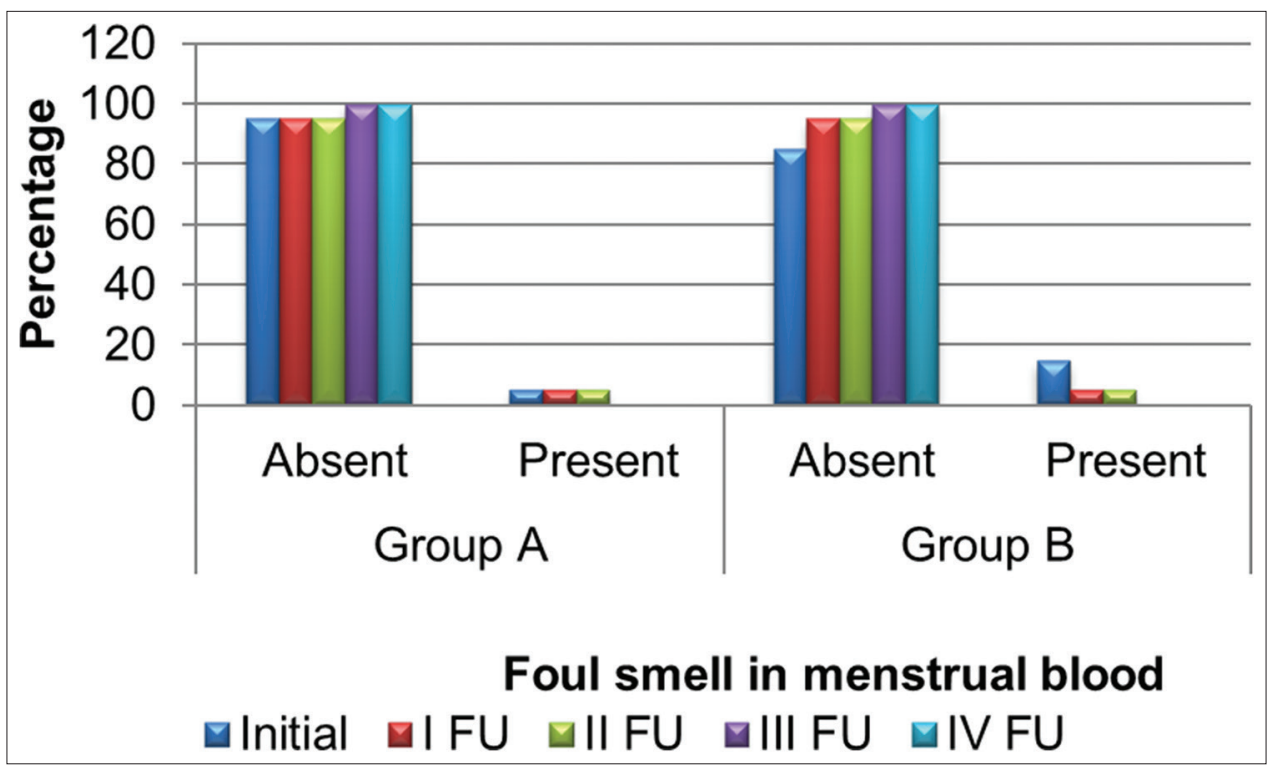

Graph 6: Changes in the smell in menstrual blood in different follow-ups in both the groups

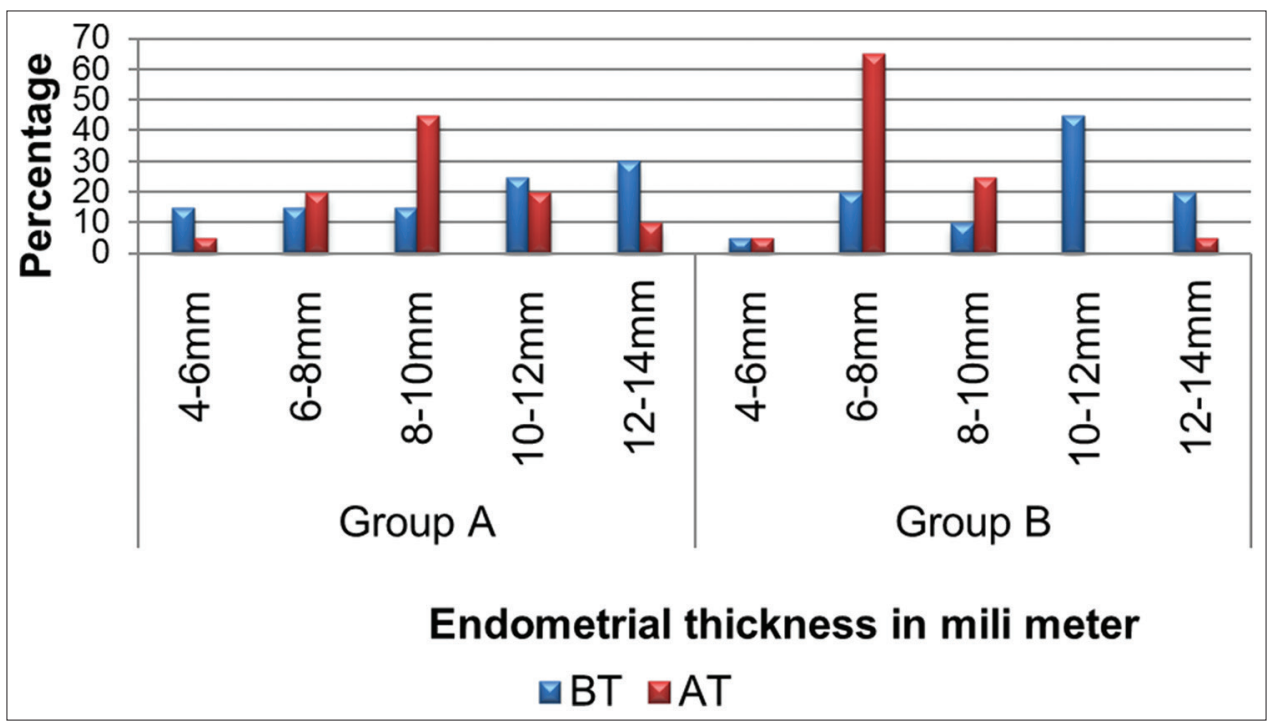

Graph 7: Changes in the endometrial thickness before and after treatment in both the groups

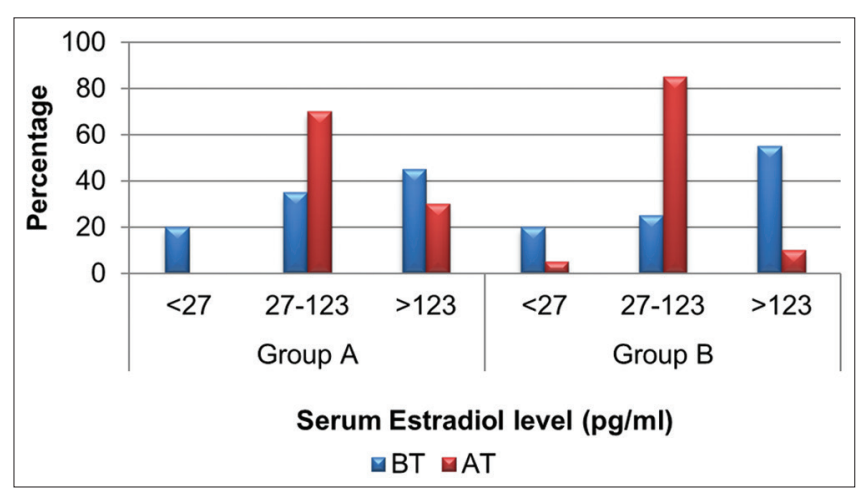

Graph 8: Changes in the level of serum estradiol before and after treatment in both the groups

Initially, $19(95 \%)$ women had a passage of clots during menstruation in both the groups. The change in consistency of menstrual blood was noticed during I follow-up in both the

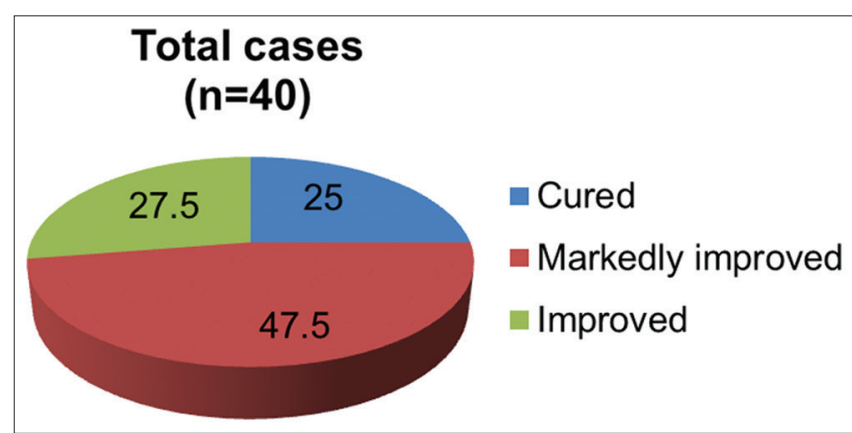

Graph 9: Percentage improvement in total number of cases in both the groups

groups. During III follow-up, clots were present in 7 (35\%) and $5(25 \%)$ patients in Groups A and B, respectively, while during IV follow-up, passage of clots was present in $4(20 \%)$ and $1(5 \%)$ women in Groups A and B, respectively. 


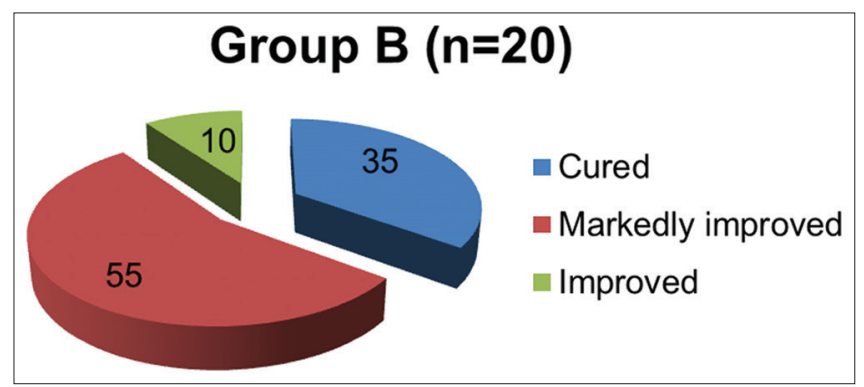

Graph 10: Percentage improvement in total number of cases in group $B$

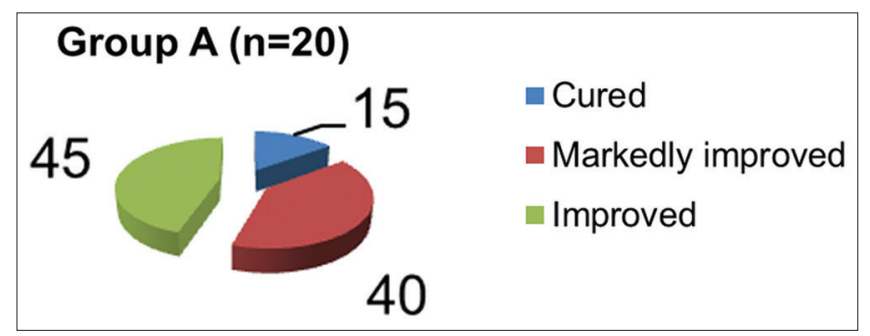

Graph 11: Percentage improvement in total number of cases in group $A$

On comparison between initial and different follow-ups, the results were highly significant in both the groups. When comparison was done between Groups A and B, non-significant results were found in each follow-up.

Initially, foul smell in menstrual blood was present in $1(5 \%)$ and $3(15 \%)$ cases of Groups A and B, respectively. Change in foul smell was seen during III follow-up in both the groups. During III follow-up, it was not present in any number of patients in both the groups. On comparison between initial and different follow-ups, the results were not significant in Groups A and B. When comparison was done between Groups A and B, the results were non-significant during each follow-up.

Initially, endometrial thickness $8-14 \mathrm{~mm}$ was seen in $14(70 \%)$ and $15(85 \%)$ women of Groups A and B, respectively, while after treatment, it was seen in $15(85 \%)$ and $6(30 \%)$ women of Groups A and B, respectively. When comparison was done before treatment and after treatment, the results were non-significant and highly significant in Groups A and B, respectively. When comparison was done between Groups A and B, highly significant results were seen after treatment in Group B in comparison to Group A.

Initially, serum estradiol level $>123 \mathrm{pg} / \mathrm{ml}$ was seen in $9(45 \%)$ and $11(55 \%)$ women of Groups A and B, respectively, while after treatment, it was seen in only $6(30 \%)$ and $2(10 \%)$ women of Groups A and B, respectively. When comparison was done before treatment and after treatment, the results were non-significant and highly significant in Groups A and B, respectively. When comparison was done between Groups A and B, non-significant results were seen after treatment in Group B in comparison to Group A.
Of total, $10(25 \%)$ women were cured, while $19(47.5 \%)$ and $11(27.5 \%)$ women were found markedly improved and improved, respectively. 3 (15\%) women were cured in Group A, while in Group B, it was observed in $7(35 \%)$ women. None of the cases had low improved and unchanged results in both the groups. Statistical difference between both the groups was significant. Percentage of markedly improved cases was higher in Group B in comparison to Group A. On comparison of both the groups, Group B showed a better result than Group A.

\section{DISCUSSION}

In healthy women of reproductive age group, normal menstrual cycle lasts from 21 to 35 days, with 2-6 days of flow. The mean menstrual blood loss per menstruation ranges between 37 and $43 \mathrm{ml}$ and $70 \%$ of the loss occurs in the $1^{\text {st }} 48 \mathrm{~h}$.

Atyartava is caused by vitiation of vata and pitta. According to Ayurvedic literature, Shatavari has madhura- tikta rasa, guru snigdha guna, madhur vipaka, and sheet virya. ${ }^{[2]}$ Due to these properties, it is able to pacify vata and pitta doshas which are responsible for the pathogenesis of Atyartava.

Uttarbasti is a unique ayurvedic procedure, which is given in Uttaramarga, i.e. urinary, vaginal, and cervical passages. It normalizes the vitiated vata dosha and has been indicated in a number of genitourinary disorders.

Selected 40 cases were divided into two groups according to their different treatment schedules. Group A was treated with oral Shatavari Churna. The oral ingestion of drugs is the oldest and most common mode of drug administration, but its action was observed slow. Some of the drug taken orally gets destroyed during first pass metabolism by the enzymes of the gastrointestinal lumen, gut wall enzymes, bacterial enzymes, and hepatic enzymes. Hence, bioavailability of oral drugs was less. That is why not so good results were seen. Group B was treated with Shatavari churna taken orally along with Uttarbasti of Shatavari taila. Since Uttarbasti is a unique method of slowly injecting medicated oil through the cervical os, it has a direct action on endometrium of uterus. Hence it acts as a topical route of drug administration wherein the drugs injected are directly absorbed through blood vessels supplying the endometrium. Uttarbasti is the topical route of drug administration where drugs act directly on the endometrium and are absorbed by the arterial wall of the endometrium. It also acts on ovary after absorption and affects the hypothalamic-pituitary-ovarian axis. Uttarbasti also stimulates certain receptors in the endometrium, leading to correction of all the physiological processes of reproductive system. In Uttarbasti therapy, along with Shatavari, tilataila is used which adds to the beneficial effects of the therapy. Taila with its sneha and sukshma gunas, may be easily absorbed through the mucous membrane, glands, and vessels, and by its steroidal action, gives nutrition and potentiates the endometrial receptors. That is why Uttarbasti Chikitsa given 
along with Shatavari churna showed better results in atyartava than administration of Shatavari churna orally alone.

Shatavari (Asparagus racemosus) is a source of phytoestrogens. These are weaker than natural estrogens in action. However, they compete with estrogen for estrogen receptors. In the presence of an excess of estrogens in the body, phytoestrogens may have antiestrogenic effect by occupying the same estrogen receptor. In conditions of low serum estrogen, phytoestrogens occupy vacant receptors and stimulate estrogenic action. ${ }^{[3]}$ Hence, whether menorrhagia is due to an excess of estrogen or reduced estrogen (atrophy of the endometrium), it can help in either of the cases.

The mineral elements found in the different parts of the plant were identified as calcium, magnesium, copper, iron, manganese, nickel, zinc, potassium, cobalt, and chromium.

The roots are considered as an astringent. ${ }^{[4]}$ Hence, they reduce the menstrual flow by this property. Moreover, Asparagus racemosus was found to be an effective antiulcerogenic and antisecretory agent ${ }^{[5]}$ and thus has its role in healing of endometrium. It is also an adaptogen. ${ }^{[3]}$ It has significant antidepressant activity, ${ }^{[6]}$ and this effect is probably mediated through the serotonergic and the noradrenergic systems and augmentation of antioxidant defenses. This helps to reduce the stress levels in the body, thus normalizing the imbalance of hormones. Hence, Group B showed better results than Group A.

\section{CONCLUSION}

The present study was conducted on 40 patients of Atyartava showed a significant trend of reduction in the complaints. Group A was treated with oral Shatavari Churna, while Group B was treated with Shatavari Churna orally along with uttarbasti of Shatavari Taila. The latter showed better results due to the direct action of Uttarbasti on pelvic organs as well as due to indirect stimulation of hypothalamic-pituitary-ovarian axis.

\section{Scope of the Further Study}

- The trial was a time limited study of 4 months, so an extended long-term trial is required for understanding the long-term effects of Shatavari on Atyartava.

- The cost of trial drug can be brought down by massive production.

- Chemical studies need to be done to understand the precise mechanism of action of the trial drug. This will potentiate the results and will open areas for further research.

\section{REFERENCES}

1. Samita K, Tantra V. Kalpa Sthanam. In: Tiwari PV, editor. Ch. 5. Varanasi: Chaukhambha Visvabharati; 2008. p. 348.

2. Sharma AP, Vigyana D. Dravya Gun Vigyana. Vol. 2. Varanasi, India: Chaukhambha Bharati Academy; 2011. p. 563.

3. Sharma K, Bhatnagar M. Asparagus racemosus (Shatavari): A versatile female tonic. Int $\mathrm{J}$ Pharm Biol Arch 2011;2:855-63.

4. Negi JS, Singh P, Joshi GP, Rawat MS, Bisht VK. Chemical constituents of asparagus. Pharmacogn Rev 2010;4:215-20.

5. Bhatnagar M, Sisodia SS. Antisecretory and antiulcer activity of Asparagus racemosus willd. Against indomethacin plus phyloric ligation-induced gastric ulcer in rats. J Herb Pharmacother 2006;6:13-20.

6. Singh GK, Garabadu D, Muruganandam AV, Joshi VK, Krishnamurthy S. Antidepressant activity of Asparagus racemosus in rodent models. Pharmacol Biochem Behav 2009;91:283-90.

7. Sharma AP. Dravya gun Vigyana. Vol. 2. Varanasi, India: Chaukhambha Bharati Academy; 2011. p. 121-2.

8. Indian Council of Medical Research. Reviews on Indian Medicinal Plants. Vol. 3. New Delhi: Indian Council of Medical Research; 2004. p. 228.

Source of Support: Nil. Conflict of Interest: None declared. 